\title{
MATERNIDADE ADOLESCENTE EM CONTEXTO CULTURAL: UM ESTUDO COM MÃES ADOLESCENTES DE DUAS COMUNIDADES (UMA URBANA E UMA SEMI-RURAL) NA BAHIA
}

\section{ADOLESCENT MOTHERHOOD IN A CULTURAL CONTEXT: A STUDY WITH ADOLESCENTS MOTHERS IN TWO COMMUNITIES (URBAN AND SEMI-RURAL) IN BAHIA}

\author{
Ana Lúcia B. Fonsêca ${ }^{1}$ \\ Ana Cecilia de S. Bastos ${ }^{2}$
}

FONSÊCA, A. L. B.; BASTOS, A. C. D. S. Maternidade adolescente em contexto cultural: um estudo com mães adolescentes de duas comunidades (uma rural e uma semi-rural) na Bahia. Reu Bras. Cresc. Desenv. Hum., S. Paulo, 11(1), 2001.

\begin{abstract}
Resumo: Este trabalho descreve como famílias de duas comunidades da Bahia enfrentam a maternidade adolescente e como o seu contexto cultural interfere nas relações de maternagem. Foram entrevistadas 20 mães adolescentes do Vale das Pedrinhas (área urbana) e 20 da Areia Branca (área semi-rural), em seus domicílios. Os resultados demonstram que o suporte familiar é imprescindível à condição da maternidade adolescente. Indicam também que as mães adolescentes da área urbana (VP) diluem mais este papel com os demais membros da família, pois todas continuavam vivendo no núcleo familiar de origem, sendo sua mãe a principal responsável pela criança. As mães adolescentes da área semi-rural constituíram, em sua maioria, o próprio núcleo familiar, sendo responsáveis elas mesmas pelo cuidado e educação do seu filho. Observa-se uma naturalização da maternidade precoce nas duas áreas, embora com maior ênfase na área semi-rural. A família é o principal ponto de referência dos indivíduos, principalmente nas comunidades de baixa renda.
\end{abstract}

Palavras-chave: família; maternidade adolescente; contexto sócio-cultural; rede de apoio.

\section{INTRODUÇÃO}

A instituição familiar já não é a mesma de décadas anteriores. Sua principal função, a de socializar os indivíduos, passou a ser exercida também por outras instituições, uma das quais é a escola. Esse fenômeno é resultante de todas as transformações sócio-econômico-culturais que vêm ocorrendo no mundo, e a família, como toda instituição social, passa por ajustes, já que é determinada por uma dinâmica rede de relações entre indivíduos e o contexto em que estão inseridos. Sendo assim, está sujeita a constantes modificações. A família é uma instituição que se estrutura, também, mediante um sistema de valores e crenças organi- zados, os quais, por sua vez, são engendrados por matrizes culturais mais gerais.

Por conta de todas as alterações por que passou e pelo fato de sua função tradicional estar sendo subsidiada ou co-exercida por outras instituições, tem-se questionado o real valor da família, tanto no que diz respeito à sua manutenção, quanto à sua capacidade de orientar e educar seus membros. Tais questões podem se fundar no padrão simbólico prevalente de que o ideal de família é aquela formada por pai, mãe e filhos, cada um exercendo um papel homogeneamente estabelecido.

Entretanto, esse padrão simbolico universal não existe. As famílias são compostas das mais diversas maneiras; das famílias extensas pais, fi-

Mestra em Educação (IFBA), professora da UNIT/Se. E-mail: analufonseca@bol.com.br

2 Doutora em Psicologia (UNB), Docente do Departamento de Psicologia e do Programa de Pós-Graduação do Instituto de Saúde Coletiva da UFBA. Pesquisadora Il-C do CNPq. E-mail: acecil@ufba.br 
lhos, parentes e agregados - até as chamadas matrifocais - mães, fillhos e netos, mesmo nas classes mais abastadas. Todas elas possuem uma dinâmica própria, determinada por tradições histórico-culturais de sua comunidade e variam conforme as estratégias de adaptação condizentes com sua realidade concreta de vida.

Além disso, como CORDEIRO (1994) afirma, a família tem papel fundamental no cenário básico dos sujeitos, estruturando normas e valores éticos, afetivos, hábitos, bem como o processo de desenvolvimento, nos vários domínios, de modo a preparar a criança para inserir-se na sociedade. A autora ainda argumenta que nenhuma outra instituição a substitui em suas funções e, muito menos, em sua importância.

O grupo familiar serve aos indivíduos como ponto de referência psíquica, mas também como suporte social para enfrentar as dificuldades cotidianas. Dentre as dificuldades mais freqüentes observadas nas últimas décadas, está a gravidez da filha adolescente. Há algum tempo atrás, este fato era visto como comum e corriqueiro. Das jovens era esperado que casassem e tivessem filhos; no mundo contemporâneo, porém, a adolescência é concebida como uma das fases do desenvolvimento humano, com especificidades e cultura próprias, cujas expectativas sociais vão além do casamento e procriação. Aliado a estas novas formas de conceber a adolescência está o fato da gravidez ocorrer cada vez mais precocemente e fora de uma relação conjugal mais estável, rompendo bruscamente o ciclo esperado de desenvolvimento da jovem, com possível impacto sobre o bemestar de seu bebê.

A constatação da gravidez precoce traz mais do que a preocupação com a adolescente em si. Além da ruptura que a maternidade pode representar nesta fase, enquanto configuradora de uma transição não-normativa no curso do desenvolvimento (COWAN, 1991), repercutindo nos níveis físico, psíquico, econômico e social, surge também a preocupação com a criança que está sendo gerada. Receia-se que essas mães não saibam e/ou não tenham condições de cuidar e educar os filhos, e que suas crianças apresentem déficits em relação aos filhos de mães mais velhas.

Todas essas preocupações com a maternidade adolescente têm gerado diversos programas de prevenção e apoio às jovens e seus bebês. Esses programas estão ligados a instituições das mais diversas áreas e ideologias, desde instituições públicas e privadas de saúde e educação até instituições religiosas. Em geral, elas têm o objetivo maior de evitar que as adolescentes engravidem, através de informações relativas à educação sexual e, às vezes, até moral. Porém, no caso da jovem já ter engravidado, algumas instituições têm se colocado na função de dar suporte, tanto material quanto psicológico.

Segundo ARCIERI (1998), o suporte social é um sistema de importância primária na determinação do comportamento parental, que ocorre por intermédio dos recursos psicológicos dos pais durante a educação dos filhos. Assim, para ele, vários são as fontes de suporte social importantes para as mães adolescentes, desde o parceiro ou marido, à família de origem dos pares, até a comunidade.

\section{A FAMÍLIA SE ADAPTA ÀS MUDANÇAS HISTÓRICAS}

Das sociedades de caçadores/coletores ao advento da Revolução industrial, as famílias eram compostas de grandes grupos de parentesco e/ ou apadrinhamento, chamados de família extensa. Nessas famílias, o meio de subsistência passou, aos poucos, da caça/coleta para a agropecuária, e todos os integrantes, da criança ao velho, participavam das atividades produtivas, não havendo separação por idade; em alguns casos, havia diferenciações por gênero.

Nesse contexto, os indivíduos aprendiam gradualmente os conhecimentos acumulados pelo grupo social no convívio e participação direta na vida da comunidade. Os mais jovens aprendiam as práticas produtivas do seu grupo observando e ajudando os mais velhos; as atividades produtivas e o lazer estavam fortemente intricadas, sem uma preocupação em distinguir um momento do outro (BRUNER, 1976).

Nessas comunidades, as crianças e jovens partilhavam da vida dos adultos desde muito cedo. A educação se dava paulatinamente, pois, como as crianças cresciam no meio dos adultos, brincando de trabalhar, imitando-os, aprendiam o ofício dos pais, preparando-se para ajudá-los quando estivessem maiores e substituindo-os na sua velhice, de modo a dar continuidade ao ciclo produtivo do grupo social.

CORDEIRO (1994) diz que a família poderia ser considerada uma unidade de produção e consumo, já que produzia grande parte das suas necessidades. Nesse ambiente a criança não era separada dos adultos; ela aprendia junto com eles, imitando-os, tendo-os como modelo, como estímulo. O desenvolvimento infantil ocorria concomitante à produção cultural, compartilhando e experimentando com os outros as experiências, fazendo parte do contexto e da história do seu grupo social (BRUNER, 1976). 
Com a Revolução Industrial e o conseqüente incremento do processo de urbanização, os padrões de comportamento e valores familiares de toda a sociedade, no mundo ocidental, sofrem profundas alterações. Esse novo modo de produção criou expectativas de melhores condições de vida para muitas famílias camponesas, levandoas a se deslocar do meio rural para o meio urbano. A princípio, elas se organizavam tendo como base os seus costumes, levando os filhos para a produção ou deixando-os em casa sob os cuidados de algum dos irmãos maiores.

Contudo, esse modo de criar filhos esbarrou nos valores e padrões de comportamento que estavam emergindo com a nova classe social, a burguesia, já com alguma influência das teorias psicológicas que preconizavam a família nuclear como modelo mais adequado à sociedade e ao indivíduo. Essas novas concepções de família e criança e adolescência iam de encontro aos modos de organização familiar tradicional nas comunidades rurais, onde havia o predomínio de famílias extensas (GOMES SZYMANSKI, 1994).

A adoção do estilo burguês de organização familiar leva os indivíduos a novos padrões de comportamento, privilegiando as relações entre seus membros, pois prevê um fechamento da família em si mesma e a evidente separação entre residência e trabalho, entre o público e o privado, razão e emoção, sexualidade e afetividade. Nesse contexto, o marido é autônomo e o provedor material da família, e a mulher é dependente e responsável pela educação dos filhos (ARCIERI, 1998).

Tal modelo determina o surgimento de novas práticas de criação de filhos, em que o relacionamento entre pais e filhos tem uma dinâmica própria, enfatizando o cuidado e afetividade da criança pelos pais, principalmente a mãe. Com sua implantação, as famílias passaram a ter um número menor de filhos, o que possibilitava um investimento mais efetivo nos cuidados e educação dos mesmos; ao mesmo tempo, a crescente valorização da cultura científica contribuía para a reafirmação da necessidade de educação escolar.

\section{A FAMILIA COMO SUPORTE À SOBREVIVÊNCIA DOS INDIVÍDUOS}

Todas as transformações por que passaram as famílias rnigrantes, as mudanças nas con

Todas as transformações por que passaram as famílias rnigrantes, as mudanças nas concepções de família, criança, juventude, educação de filhos, interferiram diretamente no comportamento dos indivíduos e, mais efetivamente, no dos jovens. Essas transformações passaram a exigir, de modo intenso, a promoção de novas e constantes estratégias adaptativas de todos os sujeitos, em especial dos adolescentes, tornando mais difícil o processo de adaptação à vida. Levaram-nas a criar estratégias adaptativas que pudessem suprir suas dificuldades de sobrevivência e de compreensão dessa nova realidade, interferindo diretamente nas formas de conceber o mundo, em seus valores e hábitos, o que contribui para tornar as relações entre os familiares e sua comunidade imprescindíveis à vida de cada sujeito.

MELLO (1994) sinaliza que essas adaptações provocam mudanças nas concepções dos sujeitos sobre si mesmo, em suas representações, no lugar que ocupam na família e no social, o que leva a percepções diferentes dos papéis e a reavaliações de expectativas que redefinem as situações com regras que têm origem no modo como os sujeitos pertencem à realidade.

O Brasil também foi atingido e passou por essas alterações sócio-econômicas. Segundo GOLDANI (1994), a partir da segunda metade do século XX, as famílias brasileiras passaram por um processo de modernização "contraditório", no qual "a tendência é de uma diminuição no tamanho e uma maior diversidade nos arranjos domésticos e familiares" (p. 7).

Nessa nova forma de organização familiar, à mãe é atribuida toda responsabilidade com os cuidados e a formação da prole, tarefa que antes era diluída entre os demais membros femininos do grupo familiar. Ao mesmo tempo, as dificuldades econômicas aceleram seu ingresso no mercado de trabalho. Após muitas reivindicações, começam a surgir as primeiras instituições para atender os filhos das mães trabalhadoras.

Quando se considera que os padrões de interação familiar e os valores de socialização são diretamente afetados pelo contexto socioeconômico e cultural, moldando as formas de estruturação das famílias (KAGITÇIBASI, 1996; RABINOVICH, 1998), pode-se imaginar que o processo histórico-cultural levou essa instituição a criar estratégias de adaptação, de modo a dar suporte psíquico e econômico a seus membros.

Portanto, todas essas mudanças estruturais e funcionais que a família vem sofrendo ao longo do tempo, para adaptar-se a toda uma nova realidade sócio-histórica, têm influído diretamente nas formas e modelos de educação dadas às crianças. Essas mudanças se expressam com clareza nas crenças e valores dos seus integrantes, que passam a ter uma nova concepção de homem e a romper com antigos padrões. No entanto, como o estabelecimento do modelo burguês de família está longe da sua realidade concreta, os pais perdem o referencial de identidade cultural, não conseguin- 
do exercer o papel de educadores junto aos filhos (CUNHA, 1997).

Hoje, as formas de organização familiar são as mais diversas, de acordo com as condições objetivas de vida. São necessários estudos capazes de abordá-las de modo a fazer evidenciar as possibilidades e modos que definem os novos contextos de desenvolvimento, avaliando suas implicações para a saúde da família e para a reconstrução de culturas pessoais (BASTOS, 2001).

No contexto brasileiro, onde as condições objetivas de vida são cada vez mais precárias, subsistem, mesmo no meio urbano-industrial, com o fortalecimento da ênfase individualista, os padrões relacionais coletivistas, nos quais os indivíduos se interrelacionam de modo a garantir a sobrevivência de todo o grupo social, o que se estende padrões às práticas de educação dos filhos (RABINOVICH, 1998).

$\mathrm{O}$ fato de os grupos familiares se estruturarem para fazer frente às dificuldades que encontram para sobreviver suscita imediatamente $o$ questionamento das possíveis relações entre valores culturais, interações sociais na família e padrões de desenvolvimento dos indivíduos. Já que o contexto de desenvolvimento ocorre em um ambiente ecológico, pelo qual todos os sistemas, do mais micro (relações face-aface, no qual se inclui a família) ao mais macro (ideologia), estão relacionados entre si (BRONFENBRENNER, (1979/ 1996), se as estruturas familiares forem alteradas, serão alteradas também as práticas de criação dos filhos.

Como LeVINE et al (1997) as práticas de criação de filhos prevalentes em uma comunidade estão diretamente associadas às metas e modelos que a organizam, de forma a dar significado a cada grupo cultural, tornando-os adaptados a uma ecologia particular.

Assim, cada grupo social e, mais especificamente, cada grupo familiar, há de possuir modos de criação e educação de filhos partilhados culturalmente, imprimindo a cada contexto específico um estilo que define a sua adaptabilidade. Dessa forma, cada indivíduo tem em si características que se articulam com seu meio e o distingue de outros pela absorção dos valores e normas que compõem seu ambiente.

\footnotetext{
A influência das variáveis culturais se mostra ainda patente no fato de que uma pessoa que é criada em uma sociedade aprende a se tornar, em alguns aspectos, igual a todas as outras daquela sociedade e diferente daque las criadas em outras sociedades. (ALENCAR, 1985, p. 22).
}

Apesar das mudanças terem influído na estruturação das famílias e a sociedade ter instituído que, se não é a mãe que cuida e educa a criança, ela deve ser cuidada e educada em uma instituição preparada para essa tarefa, enquanto os adultos, ou seja, o pai e a mãe, estão trabalhando, valorizando o distanciamento entre o mundo dos adultos, que é do trabalho, e o mundo da criança e do jovem, que é da brincadeira e do estudo.

Verifica-se que o grupo familiar tem importância primordial na educação dos indivíduos porque ele, além de ser o principal responsável pela transmissão dos padrões culturais do seu ambiente, é a base para a sua formação psíquica. A família funciona como ponto de partida e de referência para a aprendizagem das normas e valores sociais, locus no qual os sujeitos devem buscar subsídios das mais diversas ordens: afetiva, econômica e cultural.

Assim, quando uma adolescente se torna mãe, ela há de buscar apoio psíquico e econômico do seu grupo familiar e da sua comunidade, de modo a continuar o seu desenvolvimento e propiciar condições favoráveis de desenvolvimento para seu filho. Isso porque as mães adolescentes, em geral, continuam vivendo com suas famílias de origem, exercendo o papel de cuidar e educar de seu filho sob a orientação de seus pais. Nesse momento, a família cumpre seu papel social de repassar os valores culturais a seus membros e dar-lhes respaldo de forma a viabilizar sua sobrevivência.

Este trabalho objetivou de descrever como a família subsidia a mãe adolescente nas práticas de criação de seu filho e comparar duas áreas uma urbana e outra semi-rural - situadas na Região Metropolitana de Salvador, de modo a vislumbrar como as diferenças de concepções de família e adolescência interferem na dinâmica das relações familiares.

\section{MÉTODO}

As informações foram obtidas mediante entrevistas semi-dirigidas, gravadas em áudio, com 40 (quarenta) mães adolescentes, em suas respectivas residências, subdivididas em 20 (vinte) de Areia Branca, distrito pertencente ao município de Lauro de Freitas e 20 (vinte) do Vale das Pedrinhas, área situada no Nordeste de Amaralina, bairro de localização central em Salvador.

O contato com as duas áreas foi realizado de maneira distinta. No distrito de Areia Branca, a pesquisadora principal integrou-se à equipe de um 
projeto que lá se desenvolvia ${ }^{3}$, localizando as famílias com mães adolescentes mediante indicações dos próprios vizinhos ou moradores antigos da área. No Vale das Pedrinhas, onde a pesquisadorajá havia participado de atividades para adolescentes grávidas em um Centro de Saúde, as indicações foram feitas pelo contato direto com os moradores. Tanto em Areia Branca como no Vale das Pedrinhas, as próprias adolescentes indicavam outras adolescentes com filhos, em um sistema de "bola de neve". A abordagem era feita na residência das adolescentes.

A abordagem e a forma de entrevistar as mães adolescentes foi bastante similar nos dois bairros. A pesquisadora abordava as adolescentes, explicitava os objetivos da pesquisa e, apesar de algum receio inicial, houve grande receptividade, não se registrando recusas. As entrevistas foram realizadas nos mais diversos locais, sob a escolha da entrevistada: na porta da rua, na casa da vizinha, na sala de visitas, no quintal, no quarto.

Em geral, as crianças estavam por perto, como também alguns moradores da casa e da vizinhança, que circulavam em torno, participando e opinando sobre as questões. Nos casos em que a interferência tornava-se difícil de administrar, o processo era interrompido para que o ambiente recuperasse o clima propício à interação pesquisadora-entrevistada.

As entrevistas transcorreram num ambiente o mais informal possível, de modo que as perguntas fluíssem sem causar constrangimentos às entrevistadas, e nas respostas elas falassem tudo o que considerassem necessário. A1gumas adolescentes necessitavam ser mais estimuladas a falar que outras, obrigando a entrevistadora a ser mais incisiva. Esta procurava seguir o roteiro, mas sempre permitindo uma flexibilidade a fim de entender melhor os relatos ou torná-los mais claros.

\section{RESULTADOS E DISCUSSÃO}

Um tipo de estruturação familiar na qual todos necessitam estar próximos para atenuar as dificuldades de sobrevivência, é comum as avós maternas serem responsáveis pela família e por todos os seus integrantes, sendo, conseqüentemente, as que mais ajudam nos cuidados com as crianças, como principal rede de apoio social. No entanto, essa rede inclui também outros parentes e agregados.
Tabela 1. Quem ajuda nos cuidados com a criança.

\begin{tabular}{lccr}
\hline Arca & $\begin{array}{c}\text { Areia } \\
\text { Branca }\end{array}$ & $\begin{array}{c}\text { Vale das } \\
\text { Pedrinhas }\end{array}$ & \\
\hline Ajuda com & $(\%)$ & $(\%)$ & $\begin{array}{c}\text { Total } \\
\mathbf{( \% )}\end{array}$ \\
a criança & & & 67,5 \\
\hline Avós maternas & 55.0 & 70,0 & 62,5 \\
Tias & 15,0 & 0,0 & 42,5 \\
Avós paternos & 30,0 & 50,0 & 17,5 \\
Pai & 10,0 & 0,0 & 5,0 \\
Vizinhos & 10.0 & 5,0 & 7.5 \\
Ninguém & 0,0 & 5,0 & 2,5 \\
\hline
\end{tabular}

Os dados expostos na Tabela 1 evidenciam justamente essa estrutura familiar, de forma que as avós aparecem em 67,5 \% dos casos como principal fonte de suporte social para as mães adolescentes e suas crianças. As outras fontes de apoio dividem-se entre tias maternas e paternas $(42,5 \%)$, avós paternas $(12,5 \%)$, Vizinhas $(7,5 \%)$. Apenas uma diz não ter ajuda, e outra remunera alguém para cuidar das crianças enquanto trabalha fora.

Entre as tarefas relacionadas com o suporte social está a de orientar, ajudar e servir de modelo para o grupo. Quem mais orienta as mães adolescentes são suas próprias mães, em $70 \%$ dos casos. Mesmo recebendo orientação também de outras pessoas é às próprias mães, a quem elas recorrem em caso de necessidade.

Desse modo, a figura materna é o principal elemento na rede de apoio, seguido por outros familiares, como tias, bisavós, avós paternas. Em alguns casos, em Areia Branca aparece o relato de terem sido orientadas também por agentes de saúde (agentes comunitárias, médicos e enfermeiras $)^{4}$.

Esses dados confirmam a conclusão levantada por ARCAREI (1998), que afirma ser a família de origem, principalmente a avó materna, como instância mais importante na rede social de apoio para a mãe adolescente e seu bebê, enfatizando a sua importância para o desenvolvimento dessa díade.

Esse suporte torna-se primordial com a confirmação da gravidez. A reação da família à gravidez é, na maioria das vezes, negativa: em mais da metade das famílias a primeira reação é de não aceitação $(52,5 \%)$, indo da rejeição à indução ao aborto. As mães adolescentes relataram que, por fim, há uma acomodação à nova si-

3 O Programa de Saúde da Farnilia: Condições, Sujeitos e Contextos, do instituto de Saúde Coletiva da UEBA, conduzido pelas Dras. Ana Cecilia Bastos e Leny Trad.

4 Nessa área foi implantado o Programa de Saúde na Familia, cuja prática inclui visitas domiciliares por agentes de saúde, médicas e enfermeiros. 
tuação, fortalecendo os comportamentos de aceitação, que apareceram diretamente em 37,5\% das respostas, naturalizando a gravidez. Entretanto, observa-se uma pequena diferença entre as duas áreas estudadas. Em Areia Branca, as adolescentes relatam uma maior rejeição por parte das famílias (50\%) do que no Vale das Pedrinhas (25\%), apesar de que, neste, $15 \%$ das famílias passaram por conflitos decorrentes da rejeição do pai da adolescente e aceitação dos outros familiares, principalmente da mãe.

A diferença em relação às reações das famílias nas duas áreas contraria o esperado, já que as adolescentes de Areia Branca parecem ser preparadas para essa tarefa logo cedo, ao passo que, no Vale das Pedrinhas, essa função deve ser adiada o mais possível. A rejeição inicial da gravidez da filha, nas famílias daquela área, pode estar relacionada a valores como virgindade e casamento, mas também prescreve que a garota já pode "ser adulta" para assumir uma família. Este pode ser mais um dado que serve para o entendimento da formação das famílias nucleares em Areia Branca como algo diretamente articulado com as concepções próprias desse contexto cultural.

De acordo com BRONFENBRENNER (1996), o ser humano se constitui no centro de uma rede de relações abrangendo desde o nível mais micro, como a família, ao mais macro, como os valores e ideologias que o cercam. Com a rejeição da família, que de certa forma já é espera$\mathrm{da}$, as mães adolescentes se vêem obrigadas a estruturar suas vidas fora daquele ambiente doméstico, pressionando o pai da criança a assumir a paternidade de modo mais efetivo. Muito embora estejam sempre utilizando o respaldo das suas famílias de origem como ponto de referência, pode-se perceber este aspecto através do relato dessa mãe adolescente em relação às reações familiares à sua gravidez e à estruturação do seu núcleo familiar.

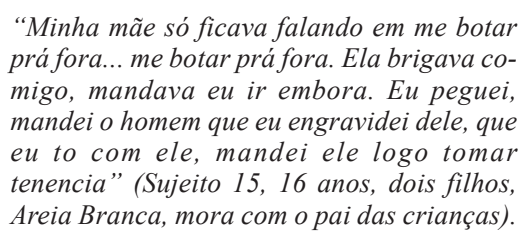

"Minha mãe só ficava falando em me botar prá fora... me botar prá fora. Ela brigava comigo, mandava eu ir embora. Eu peguei, mandei o homem que eu engravidei dele, que eu to com ele, mandei ele logo tomar tenencia" (Sujeito 15, 16 anos, dois filhos, Areia Branca, mora com o pai das crianças).

No geral, as adolescentes afirmam que a rejeição é maior por parte de outros familiares, principalmente os pais e as avós, enquanto afirmam que suas mães são as que mais as apoiam, o que leva à formulação de duas hipóteses explicativas:

1 - as mães sentem-se responsáveis pela gravidez das filhas adolescentes porque consideram que deveriam tê-las orientado e mantido sob seu controle e vigilância;

2 - algumas delas têm, na própria história, a experiência de uma gravidez na juventude, razão pela qual tendem a apoiar a filha nesse momento.

Grande parte dos pais das crianças, nos dois grupos, reagiram positivamente. A aceitação apareceu nas expressões verbalizadas pelas mães adolescentes nas expressões: "assumiu" (52,5\%), "alegre" $(17,5 \%)$. Contudo, também foram registrados relatos de rejeição: "não era o pai" $(20 \%)$, "pediu pra tirar" $(2,5 \%)$, "medo da família dele" (2,5\%), "nada" (2,5\%) "não quis saber" $(2,5 \%)$. As reações de aceitação e alegria, entretanto, não garantem uma paternidade responsável, pois muitos dos pais, embora "assurnindo" o filho, contribuem muito pouco para sua subsistência e educação, mesmo aqueles que coabitam com elas. Em geral, as mães adolescentes recorrem às suas famílias; o comprometimento com a paternidade ainda é reduzido, portanto, nas áreas observadas.

Quando a adolescente engravida, ela "queima" uma etapa, pois agora é responsável pelos cuidados do seu filho e, algumas vezes, mesmo que não cuide da criança, a família passa a controlá-la mais de perto para evitar que engravide novamente. Aquelas que constituem sua própria família passam a ter uma vida de adulto, responsáveis pelos cuidados com o filho e pela administração da casa e, em alguns casos, tornam-se responsáveis inclusive pelo sustento da família. Nos contextos mais rurais, elas já vêm sendo preparadas para assumirem essas tarefas; nos contextos mais urbanos, porém, a preparação é relativamente menos intensa e há uma diferente atribuição de papéis sociais ao adolescente. A familia desaprova a gravidez de forma mais explícita e admite mais alternativas na trajetória do jovem rumo à vida adulta. Tais diferenças possivelmente seriam mais nítidas caso o estudo tivesse abordado adolescentes de classes médias.

Entretanto, os dados relativos aos cuidados com as crianças levaram à constatação de que quase todas as mães adolescentes das duas áreas têm algum tipo de experiência com o cuidado de crianças $(75 \%)$, anterior a seu filho; muitas foram babás e/ou cuidaram dos irmãos menores. Quando questionadas sobre a existência de diferença entre os cuidados e sentimentos ao lidar com seu filho e o filho de outra pessoa, as adolescentes com experiência dividiram as opiniões. Metade diz que não há diferença, "que cuida igual", embora algumas coloquem que se sentem mais felizes quando cuidam do próprio filho. A outra 
metade afirma que há diferença, pelas mais diversas razões, desde fazer do jeito que quer, até poder punir seu filho.

Pelos relatos colhidos, $57,5 \%$ das mães adolescentes são as principais responsáveis pelos cuidados das suas crianças. Em Areia Branca as mães adolescentes eram as maiores responsáveis pelo cuidado dos seus filhos $(70 \%)$; já no Vale das Pedrinhas somente a metade cuidava deles mais diretamente. Em ambas, a maioria delas recebia alguma ajuda de outros parentes, em geral a avó materna, avó paterna, tias, o pai da criança e vizinhas. Apenas uma em Areia Branca remunera alguém para cuidar das crianças, porque trabalha fora. No grupo do Vale das Pedrinhas havia três casos $(15 \%)$ em que as crianças eram cuidadas mais diretamente pelas avós maternas e paternas; as mães adolescentes apenas as auxiliavam.

Como é possível visualizar na Tabela 2, nas tarefas de cuidados com as crianças, as mães adolescentes das duas áreas afirmaram que gostavam mais de realizar tarefas de limpeza $(62,5)$, alimentação ( $12,5 \%)$, colocar para dormir (5\%), brincar e acarinhar $(7,5 \%)$ e fazer tudo ( $17,5 \%)$. Essas tarefas não foram relatadas separadamente, vindo às vezes conjugadas.

Tabela 2. Tarefas de cuidado preferidas pelas mães adolescentes.

\begin{tabular}{lr}
\hline Tarefas de cuidado com a criança & \multicolumn{1}{c}{$\%$} \\
\hline Limpeza & 62,5 \\
Alimentar & 12,5 \\
Colocar para dormir & 5,0 \\
Brincar e acarinhar & 7,5 \\
Fazer tudo & 17,5 \\
\hline
\end{tabular}

A Tabela 3 mostra aquelas tarefas consideradas mais desagradáveis para as mães adolescentes. Nos dois grupos mais de um terço afirmou não desgostar de nenhuma $(37,5 \%)$, as demais referiram a lavar roupa $(30,0)$, limpar $(7,5 \%)$, alimentar $(12,5 \%)$, bater e carregar $(5 \%)$, levar ao médico $(2,5 \%)$ e colocar para dormir $(2,5 \%)$. Mesmo assim, elas afirmaram que não deixavam de fazê-las e que só esporadicamente pediam a alguém para substituí-las.

Entretanto, pode-se pensar que o próprio contexto dá aos individuos estratégias para a superação de algumas dessas ausências, já que nesses ambientes as crianças são cuidadas por várias pessoas que integram sua rede de relações, ampliando suas possibilidades afetivas e de estímulos.

Como os relatos informam, as mães adolescentes, em geral, têm algum tipo de ajuda nos cuidados com as crianças. Mesmo assim, como pode ser visto na Tabela 4 , cerca de $60 \%$ delas são responsáveis pela comida e banho das crianças, sendo que em Areia Branca elas assumem mais essa tarefa $(70 \%)$ do que no Vale das Pedrinhas $(50 \%)$; as outras dividem essas tarefas com as avós maternas das crianças, as tias, os pais e, eventualmente, com as avós patemas ou vizinhas.

Com relação a colocar as crianças para dormir, quem o faz também, em mais da metade dos casos, é a mãe adolescente (55\%), mas ao contrário da alimentação e da limpeza das crianças, as mães adolescentes do Vale das Pedrinhas tomavam mais para si a tarefa de colocar as crianças para dormir (65\%) que em Areia Branca $(50 \%)$. Todas as outras o fazem com o auxilio das avós maternas, pais das crianças, tias e avós paternas. Há também situações em que a criança não necessita ser colocada para dormir. Esses dados constam da Tabela 5.

Tabela 3. Tarefas de cuidado com as crianças mais desagradáveis segundo as mães adolescentes.

\begin{tabular}{lr}
\hline Tarefas de cuidado com a criança & $\%$ \\
\hline Limpeza & 7.5 \\
Alimentar & 12.5 \\
Colocar para dormir & 5.0 \\
Bater/carregar & 5.0 \\
Lavar roupa & 30.0 \\
Levar no médico & 2.5 \\
Nenhuma & 37.5 \\
\hline
\end{tabular}

Tabela 4. Quem cuida da comida e do banho da criança.

\begin{tabular}{lccc}
\hline \multicolumn{1}{c}{ Área } & $\begin{array}{c}\text { Areia } \\
\text { Branca }\end{array}$ & $\begin{array}{c}\text { Vale das } \\
\text { Pedrinhas }\end{array}$ & \\
\cline { 1 - 3 } \multicolumn{1}{c}{ Quem cuida } & \multicolumn{1}{c}{$\%$} & $\%$ & Total \% \\
\cline { 1 - 2 } Mãe adolescentes & \multicolumn{7}{c}{$\% .0$} & 50.0 & 60 \\
Mãe + avós + tias & 20.0 & 30.0 & 22.5 \\
Somente avós & 0.0 & 10.0 & 5.0 \\
Todos & 10.0 & 10.0 & 12.5 \\
\hline
\end{tabular}

Tabela 5. Quem coloca a criança para dormir.

\begin{tabular}{lccr}
\hline \multicolumn{1}{c}{ Área } & $\begin{array}{c}\text { Areia } \\
\text { Branca }\end{array}$ & $\begin{array}{c}\text { Vale das } \\
\text { Pedrinhas }\end{array}$ & \\
\cline { 1 - 3 } $\begin{array}{l}\text { Quem coloca } \\
\text { para dormir }\end{array}$ & $\%$ & $\%$ & $\begin{array}{c}\text { Total } \\
\%\end{array}$ \\
\cline { 1 - 3 } Mãe adolescentes & 50.0 & 65.0 & 55.0 \\
Mãe adol + avós & 25.0 & 7.5 & 17.5 \\
Pai da criança & 5.0 & 0.0 & 2.5 \\
Somente avós & 0.0 & 17.5 & 10.0 \\
Ninguém & 10.0 & 5.0 & 7.5 \\
Todos & 10.0 & 5.0 & 7.5 \\
\hline
\end{tabular}


As mães adolescentes de Areia Branca estão mais diretamente ligadas aos cuidados com seus filhos no que diz respeito à alimentação e à higiene, enquanto no Vale das Pedrinhas, elas assumem mais a tarefa de colocá-las para dormir, diluindo aquela tarefa com outros integrantes da familia, em especial a avó materna. Pode-se supor que, em Areia Branca, pelo fato das mães adolescentes serem as "donas de casa", com a responsabilidade dos encargos com alimentação e higiene da familia, elas assumam mais efetivamente a preparação e distribuição da alimentação entre seus membros, enquanto que, no Vale das Pedrinhas, essa tarefa é mais efetivamente praticada pela mãe da adolescente e, na sua ausência, pela filha.

O local onde as crianças dormem, nos dois grupos, foi bastante similar. Na Tabela 6 constata-se que a maior parte delas dorme na cama $(82,5 \%)$. As que dormiam na cama a partilhavam com a mãe $(47,5 \%)$ ou com o pai e a mãe $(22,5 \%)$, ou com algum outro parente $(10 \%)$, geralmente a avó materna; apenas duas (5\%) dormiam na cama sozinhas (ver Tabela 7).

Tabela 6. Local onde as crianças dormem.

\begin{tabular}{cc}
\hline Local & Total $(\%)$ \\
\hline Cama & 82.5 \\
Berço & 17.5 \\
\hline
\end{tabular}

Tabela 7. Com quem as crianças dormem.

\begin{tabular}{cc}
\hline Com quem dormem & Total (\%) \\
\hline Mãe adolescente & 47.5 \\
Mãe e pai & 22.5 \\
Outras pessoas & 10.0 \\
Sozinhas & 5.0 \\
\hline
\end{tabular}

O modo de dormir das famílias de Areia Branca e Vale das Pedrinhas é do tipo co-sleeping e, mesmo quando existe o "cantinho do bebê", seja um espaço na cama do adulto ou o berço, ele é organizado de modo a caracterizar o espaço infantil, colocado bem próximo à cama do adulto que acompanha seu sono. Esse modo de dormir das famílias urbano-rurais de baixa renda, como afirma RABINOVICH (1998), caracteriza o modo de cuidar de uma determinada comunidade cuja matriz é de uma cultura relacional calcada no contato corporal, com evidente significado para o desenvolvimento dos padrões de apego.

O brincar com a criança é muito diluído entre todos os moradores da casa, vizinhos e amigos, ficando mais restrito quando os pais moram sozinhos. Mas como, em geral, eles têm famílias nas proximidades, elas absorvem essa tarefa para si.
As brincadeiras com as crianças são partilhadas por todos os familiares e vizinhos nas duas áreas, pelo fato dessas crianças viverem rodeadas de muitas pessoas aparentadas, permitindo uma dinâmica rede de relações e troca de experiências.

Esses dados apontam para a questão dos valores culturais embutidos em algumas tarefas domésticas, que podem estar de acordo com as concepções de vida e as facilidades de acesso aos recursos materiais da comunidade. Dessa forma, as tarefas domésticas são distribuídas por todos de acordo com a importância da tarefa na vida da família, relativa aos valores disseminados para a idade e o sexo de cada membro da família na comunidade (BASTOS, 2001).

A fim de dar alguma visibilidade ao modo como os valores culturais, embutidos em cada tarefa doméstica e de cuidado às crianças, estão relacionados com os cuidados cotidianos (definidos muitas vezes pelas condições soócio-econômicas de cada família, de modo a dar conta da sobrevivência dos seus integrantes), são trazidos, a seguir, alguns padrões de cuidados cotidianos, em diferentes estruturas de família, em torno da chegada de um filho para a mãe adolescente.

\section{1 - Família matrifocal: avó materna, filhos adolescentes (entre os quais a mãe adolescente) e netos}

Inclui-se nessa categoria uma mãe adolescente atualmente com 20 anos (sujeito 13), dois filhos, um de 36 meses e outro de 16 meses, grávida do terceiro, morando com a mãe e as crianças em Areia Branca. O pai das duas crianças aparece para dar a despesa das crianças e ela está grávida de um outro homem. A mãe adolescente relata que ela e a mãe fazem tudo para as crianças, depende apenas da disponibilidade do momento. Elas alimentam e banham as crianças, mas quem faz a comida é sua mãe, segundo ela por estar "mais acostumada". Quando querem que as crianças durmam, a maior deita com a avó e dorme com ela na cama. O menor dorme com a mãe em sua cama. As crianças brincam com todos os familiares e vizinhos.

\section{II - Família nuclear típica: pai, mãe adolescente e filhos}

Esta mãe (sujeito 07) tem 20 anos, dois filhos, um de trinta e seis meses e outra de onze meses e mora com o pai das crianças em $\mathrm{AB}$, desde que engravidou da primeira criança. Ela relata que faz tudo para suas crianças, e só conta com a ajuda de sua mãe quando precisa ir ao médico. Somente à noite é que o pai das crianças ajuda a colocá-las para dormir, a maior dorme na cama com eles e a menor no berço. Quem mais brinca 
com as crianças é a mãe, mas quando está na porta da casa ou na casa dos parentes, elas brincam com todos.

\section{- Família extensa típica: avós maternos, filhos adolescentes (entre os quais a mãe adolescente) e netos \\ E este o caso de uma mãe de 17 anos (su-} jeito 21) com um filho de seis meses, morando ambos com a mãe, pai, irmã, irmão, sobrinha e a criança, no Vale das Pedrinhas. Quem cuida, alimenta e limpa a criança, e faz a comida é a mãe dela, a adolescente "apenas ajuda". A tarefa de colocar para dormir é desempenhada pela pessoa que estiver com ela, que depois a coloca na cama aonde já dormem a mãe adolescente e sua própria mãe. Todos na casa e na vizinhança brincam com a criança.

\section{IV - Família do pai das crianças: avó paterna, filhos (entre os quais o pai adolescente), mãe adolescente e netos \\ Esta é uma mãe de 19 anos (sujeito 38),} com dois filhos, um de trinta e seis meses e outro de vinte e quatro meses. Mora com o pai das crianças, a mãe dele, vários irmãos e irmãs e suas crianças no Vale das Pedrinhas. A mãe adolescente fala que é a sogra quem prepara e distribui a comida. Ela, o companheiro ou a sogra dividem a tarefa de alimentar as crianças. Quem dá banho ou as coloca para dormir é a mae e o pai c as crianças, que dormem sozinhas na própria cama. Todos brincam com elas em casa.

Nos exemplos acima fica claro que apenas no caso em que a mãe adolescente ocupa o lugar de "dona da casa" ela responde diretamente por todas as tarefas de cuidado e alimentação, não somente das suas crianças como do companheiro. Mesmo assim, ela sempre recorre à sua mãe em caso de necessidade. Nas demais estruturas familiares, ela pode até realizar algumas tarefas, mas está submetida à figura central, seja a sua mãe ou a mãe do companheiro.

Nesses contextos, em todos os casos entrevistados pela pesquisa, ela divide o papel de protagonista com a "dona da casa" (a mãe ou avó da adolescente, mãe ou avó do seu companheiro) mesmo que esta não seja a provedora dos recursos financeiros da família. Elas, efetivamente, são responsáveis pela manutenção e funcionamento da dinâmica familiar e toda sua rede de relações, tendo como base para essa dinâmica os valores e normas culturais da comunidade, determinados pelas dificuldades reais do cotidiano.

Todas essas mães adolescentes, em algum momento da gestação e pelo menos em uma gravidez, tiveram acompanhamento pré-natal nos ser- viços de saúde locais ligados ao Sistema Único de Saúde. Seus filhos, igualmente, foram assistidos nos primeiros meses, com alguma regularidade. Mesmo assim, os serviços de saúde ou qualquer outro equipamento comunitário não apareceram no relato das mães entrevistadas como participando, em qualquer nível, de sua rede de apoio social.

\section{CONCLUSÃO}

Constata-se, nesse estudo, que o suporte familiar é imprescindível às mães adolescentes, tendo em vista o papel pervasivo pelas mães e familiares da mãe adolescente no cuidado e educação de seus fillhos. A família é o principal, praticamente o único ponto de apoio (houve apenas uma referência à orientação dada por um agente comunitário de saúde). As jovens que mais recorrem a esse suporte são aquelas que continuam coabitando com a família de origem. Essas adolescentes parecem ter mais dificuldades de exercer a maternidade, continuando no papel de filhas dependentes, sendo o bebê responsabilidade dos seus familiares; elas dividem com a família os cuidados da criança, diluindo o seu papel de mãe. Já as mães adolescentes que constituem seu próprio núcleo familiar assumem diferente postura quanto à criação dos seus filhos.

A diferença entre constituir seu próprio núcleo familiar e continuar morando com a família de origem está diretamente relacionada com as condições concretas de subsistência e espaço físico, estabelecendo formas de relacionamento interpessoais e concepções culturais distintas que interferem na estruturação das famílias e nas suas práticas de criação de fillhos. Ao evidenciar a interdependência entre cultura, concepções e práticas educativas, particularmente arranjos cotidianos de cuidado, esses resultados são convergentes com os trabalhos de KAGITÇIBASI (1996), RABINOVICH (1998) e BASTOS (2001). A ecologia das mães adolescentes permite vislumbrar heterogeneidades na estruturação de suas famílias e suas práticas de criação de filhos, influenciadas não apenas pelas condições sócio-econômicas e ambientais, como também, pelos valores culturais de cada contexto, como analisa BRONFENBRENNER (1996).

No entanto, não se pode afirmar que essa variedade nos arranjos familiares, comumente associada às transformações decorrentes da revolução industrial e do processo de urbanização (GOLDANI, 1994), nunca tenha existido, seja para atender a necessidades objetivas de vida, seja pela natureza da organização cultural própria à 
espécie humana. Mais uma vez, as mudanças contribuíram para o surgimento de novos arranjos, que conservam como principal fonte de suporte a própria família e recursos informais da comunidade. O reconhecimento da gravidez adolescente como questão de grande interesse social e até como um problema de saúde pública, dadas algumas de suas conseqüências, mesmo evidenciando a necessidade de fortalecer a família, não foi capaz ainda de assegurar a presença de rede de solidariedade efetiva no apoio a famílias em momentos de transição e de enfrentamento de dificuldades.

\begin{abstract}
This work describes how families Dom two communities in Bahia cope with adolescent motherhood and how their cultural context interferes in the relationship mother-child. Twenty adolescent mothers from Vale das Pedrinhas (urban arca) and another twenty from Areia Branca (semi-rural arca) were interviewed at home. The resulte emphasize family support as a central element in lhe adolescent mother's condition and also that the adolescent mothers from lhe urban arca (VP) share more this role with the other family members, because ali the mothers continued living in their original family nucleus, and theirmothers were mainly responsible for the child. The majority of adolescent mothers from the semi-rural arca (AB) constituted themselves their own family nucleus, being the only responsible for the child's caring and education. It was possible to observe the naturalization of precocious maternity in the two arcas; however, it was stronger in the semi-rural arca (AB). The family is the main reference point of the individuals, specially in lowincome communities.
\end{abstract}

Key-words: family; adolescent motherhood; cultural context; social support.

\section{REFERÊNCIAS BIBLIOGRÁFICAS}

ALENCAR, E.M. L. S. d. A criança na família e na sociedade. Petrópolis: Vozes, 1985.

ARCIERI, J. B. C. A mãe jovem e o seu primeiro bebê. São Paulo, 1998. Tese (Doutorado) - Instituto de Psicologia da Universidade de São Paulo.

BASTOS, A.C. d. S. Idéias sobre criação de filhos: Uma invenção cultural. Psico, Porto Alegre, 22 (2), 1991.

BASTOS, A. C. d. S. Modos de partilhar: A criança e o cotidiano da família. Taubaté, SP: Cabral Editora Universitária,2001.

BRONFENBRENNER, U. A ecologia do desenvolvimento humano: Experimentos naturais e planejados. Trad. Maria Adriana Verissímo Veronese. Porto Alegre: Artes Médicas, 1979/ 1996.

BRUNER, J. S. Nature and uses of immaturity. In: BRUNER, J.S., ATOLA, A; SYLVA, K. (Eds.). Playits role in development anti evolution. London: PenguinBooks, 1976.

CORDEIRO, E. Educação inicial: porque trabalhar com a familia. Cadernos de Desenvolvimento Infantil, Curitiba, 1 (1): 17-26,1994.

COWAN, P. A. (1991). Individual and family life transitions: a proposal for a new definition. Em RA. COWAN \& E. M. HETHERINGTON (Orgs.). Family transitions. Hillsdale, NJ: Lawrence Erlbaum Associates, Inc.
CUNHA, M. V. A desqualificação da família para educar. Cadernos de Pesquisa, São Paulo, 103: 46-64,1997.

GOLDANI, A M. As famílias brasileiras: mudanças e perspectivas. Cadernos de Pesquisa, São Paulo, 91: 7-22, nov. 1994.

GOMES SZYMANSKI, H. Educação para a família: uma proposta de trabalho preventivo. Revista Brasileira de Crescimento e Desenvolvimento Humano, SãoPaulo, 4 (1): 3439,jan./jun.1994.

LEVINE, R., DIXON, S., LEVINE, S., et al. Is culture lhe most important influence in human development? Contemporary Psychology, [s. 1.], 42 (2): 165-166, 1997.

KAGITÇIBASI, Ç. The autonomous - relational self: A new syntesis. European Psychologist, [s.L.], 1 (3): 180-186,1996.

MELLO, S. L. d. Famílias das classes populares: tradições e mudança. Revista Brasileira de Crescimento e Desenvolvimento Humano, São Paulo, 4 (1): 21-27,1994.

RABINOVICH, E. P. Modos de morar no Brasil e contexto de desenvolvimento. Reunião Anual de Psicologia. 28., Ribeirão Preto, 1998. Simpósio: Contexto de desenvolvimento infantil: espaço, cultura e adaptação.

RABINOVICH, E.P. Estudo comparativo do modo d dormir e mamar de crianças brasileiras em contex tos sócio-familiares urbano e rural. Interfaces. Revista de Psicologia, Salvador, 2 (1): 41-49,1999

Recebido em 25/08/200 